\title{
Research Paper \\ Development, Effects, and Outcomes of NGOs in Villages of Roshtkhar County: A Case Study
}

\author{
Khadijeh Javani ${ }^{1},{ }^{*}$ Khadijeh Bozarjmehri ${ }^{2}$, Hamid Shayan ${ }^{3}$, Maryam Ghasemi $^{4}$
}

1. PhD Candidate, Department of Geography, Dr. Ali Shariati Faculty of Letters and Humanities, Ferdowsi University of Mashhad, Mashhad, Iran. 2. Associate Professor, Department of Geography, Dr. Ali Shariati Faculty of Letters and Humanities, Ferdowsi University of Mashhad, Mashhad, Iran 3. Professor, Department of Geography, Dr. Ali Shariati Faculty of Letters and Humanities, Ferdowsi University of Mashhad, Mashhad, Iran.

4. Assistant Professor, Department of Geography, Dr. Ali Shariati Faculty of Letters and Humanities, Ferdowsi University of Mashhad, Mashhad, Iran.

Received: 29 Jun. 2016 Accepted: 11 Dec. 2017

Keywords: Non-governmental organization (NGO), Grounded Theory, Roshtkhar County, Rural development chtation: Javani, Kh., Bozarjmehri Kh., Shayan, H., \& Ghasemi, M. (2017). [Status of NGOs in Rural Areas: Formation Process, Implications Case Study Villages' City Roshtkhar (Persian)]. Journal of Rural Research, 8(1), 152-167. http://dx.doi. org $/ 10.21859 /$ jjr-080110

: http://dx.doi.org/10.21859/jjr-080110

\section{A B STRACT}

Local non-governmental organizations (NGOs) represent participation of the people and pave the way of sustainable development objectives. This research mainly aimed to investigate the conditions and outcomes of the development of local NGOs in the villages of Roshtkhar County. The required data for the study were obtained through semi-structured interviews with a selected sample of founders and active members of NGOs ( $n=27)$. Using conventional coding process of Grounded theory, the interview texts were analyzed and the findings of the analysis matrix template were compiled by 85 open codes, 24 axial codes, and 7 selective codes. With regard to the designed pattern, NGOs in rural areas of Roshtkhar County have been founded by certain objectives and factual conditions such as economic and social factors as well as influence of internal and external factors, and also context conditions like ecological, cultural, and religious ones. Thus, the expansion of these organizations in susceptible rural areas has resulted in various social, economic, and environmental outcomes. Most important problems facing NGOs in rural areas are people's misunderstanding of the functions of NGOs in the village, shortage of budget, cultural poverty, NGOs' unsuccessful previous experiences, and negative attitudes towards NGOs in rural areas.

\section{Extended Abstract}

\section{Introduction}

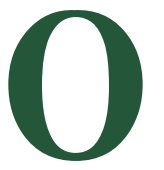

ne of the human communities whose urgent development has been paid attention to more than ever is rural community, a community that its underdevelopment makes it always a vulnerable society in rural development programs in spite of its vast participation in social-economic sector. Local non-governmental organizations (NGOs) as the representation of people's participation pave the way toward sustainable development goals. Local NGOs function in various ways around the world and regarding its verbal context are referred to a variety of organizations. In its broadest term, NGO refers to an organization that is not directly part of the government, but plays a very important role as an intermediary between people (community atoms) and authorities and even the community itself. In general, institutions are rules of the game in a society, or more deliberately, are the constraints imposed by human beings who form mutual relations of humans with each other.

\section{Methodology}

According to the research paradigm, this study is a qualitative research and has been conducted to explore

\section{* Corresponding Author:}

Khadijeh Bozarjmehri, PhD

Address: Department of Geography, Faculty of Letters and Humanities, Ferdowsi University of Mashhad, Mashhad, Iran.

Tel: +98 (915) 5199112

E-mail: azar@um.ac.ir 
the effects and outcomes of NGOs in rural areas. In this study and based on the Grounded theory, we used the qualitative semi-structured sound interviews to collect the related information and data. The study population comprised founding and directing board members of non-governmental organizations (Young Farmers and Rural Micro-credit Fund clubs) in 10 villages of Roshtkhar County. In performing interviews, we used purposive sampling technique, including remarkable and exemplary subjects (interviews with experienced, well-known and with the ability to provide the required information), snowball method (interviews with those introduced by other samples), and convenience method (interview with available samples and repeating interviews with samples who provided comprehensive information in order to gain additional points or removing existing ambiguities with respect to the information required and the progress made in achieving the theoretic saturation and conceptual richness). Choosing the samples and data collection process continued until reaching theoretical saturation level or useful information threshold. In this regard, 27 subjects $(n=72)$ were interviewed (17 males and 10 females). In total, 33 interviews (including 27 interviews in the first phase and 6 cases of repeated interviews) were carried out. For conducting systematic interviews, an interviewer protocol (including technical specifications and key questions) was compiled and used.

\section{Results}

In this study, analysis and presentation of results of the interviews was based on combination of conceptual categorization coding and the common coding process in Grounded Theory, including three coding process of open coding, axial, and selective, and finally figuring out the related themes and concepts. These steps are always linked together and overlap, and step by step takes a more abstract form with respect to the original text. During the coding in this study, some codes or actually themes and concepts were derived directly from the content of the interviews and interviewees' statements (Expressed codes) and others were realized by the researcher with regard to the concepts and contents taken by the review of current literature in the field of NGOs and empirical evidence (default codes or researcher-made codes). After compiling open codes ( 85 codes) through qualitative content analysis and directly from the words of the interviewees, in the next stage, i.e., axial coding, we started to choose themes and core concepts from open codes. In the meantime, we tried to choose those codes (from open codes) that could represent and cover other codes and be categorized under some themes. In other words, if open codes were consid- ered as micro concepts and themes, then the axial codes ( 24 codes) are framework or general concepts. Finally, by reviewing and conceptual classification of axial codes, the macro concepts and selective codes ( 7 codes) were derived. These codes are components of plotting the representative pattern of NGOs status in rural areas.

\section{Discussion}

NGOs in rural areas have developed due to convergence and synergy of different systems in a given context with the objectivs and causes such as economic, social causes and influence of internal and external factors, as well as underlying conditions like ecological conditions, culture and religion or beliefs. The growth and development of these organizations in susceptible rural areas has contributed to important economic results such as preserving water resources, agricultural land consolidation, extension of the area under cultivation of products compatible with the area, business development, educating modern methods of agriculture, processing agricultural products, also social results such as creating spirit of belonging among rural youth, empowering rural women and girls, and increasing collaboration and cooperation among villagers and finally environmental results such as using indigenous knowledge to eliminate pests and increasing people's understanding and cooperation in environmental protection.

\section{Conclusion}

The findings of this research indicate the multiple effects of NGOs on people's lives in rural areas and also the mutual influence of internal and external factors on creating these institutions. Accordingly, we can conclude that rural non-governmental organization (Young Farmers Club) in the studied villages is not merely an unofficial and promotive organization and the intermediary between individual people and the ruling authorities, but it has executive functions and active in various social, cultural, economic, and environmental fields, that represents a multi-functional feature of active NGOs in rural areas. From the perspective of this pattern, the status of NGOs in rural areas is like a process that its development and maintenance needs the availability of various factors and they continue to function by providing these conditions like a network.

\section{Acknowledgments}

This research was extracted from the $\mathrm{PhD}$ thesis of the first author, in the Department of Geography, Dr. Ali Shariati Faculty of Letters and Humanities, Ferdowsi University of Mashhad, Mashhad, Iran. 


\section{Conflict of Interest}

The authors declared no conflicts of interest. 


\title{
وضعيت سازمان هاى مردمنهاد در روستاها: فر آيند شكل رويرى، آثار و يايامدها (منطقه مورد مطالعه روستاهاى شهرستان رشتخوار مرنهار
}

\author{
خديجه جوانى'، "خديجه بوزرجمهرى"، حميد شايان"، مريم قاسمى" \\ ا - دانشجوى دكتراء كروه جغرافيا، دانشكده ادبيات و علوم أسانى دكتر على شريعتى، دانشكاه فردوسى، مشهيده ايران.

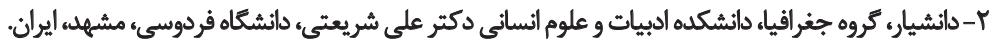

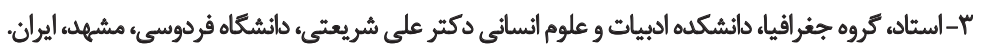

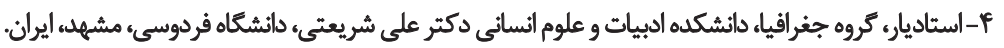

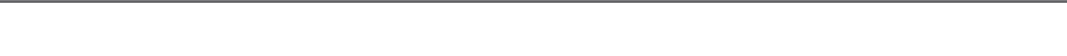

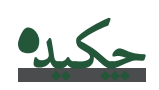

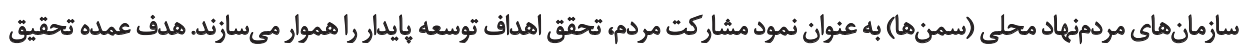

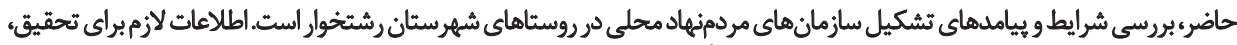

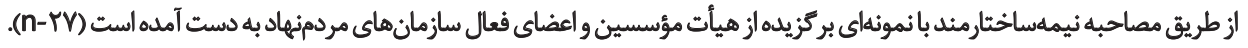

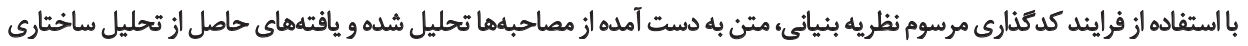

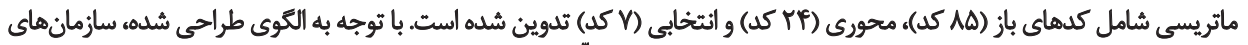

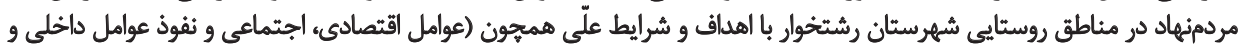

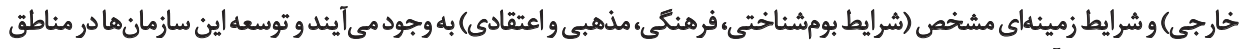

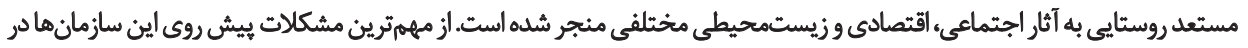

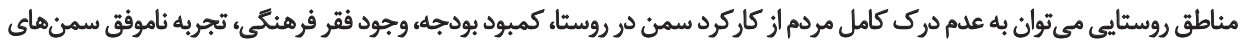

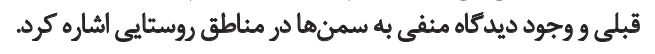

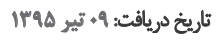

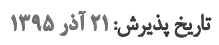

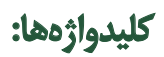
سازمان مردمنهاد (سمنها)، نظريه بنياني، شهرستان رشتخوار، توسعه نوسئ روستئيى

ادارى يا جامعهشناسى نيز از تعاريف مشخصى ثبعيت نمى إشود.

date

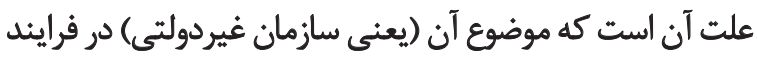

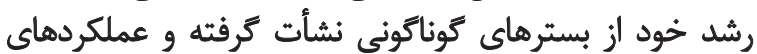

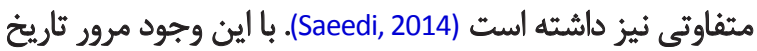

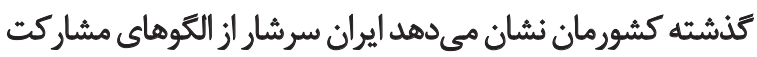

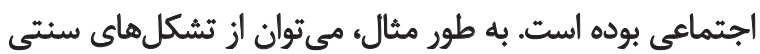

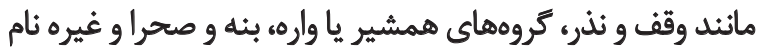

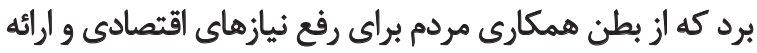
خدمات اساسى ظاهر شدهاند.

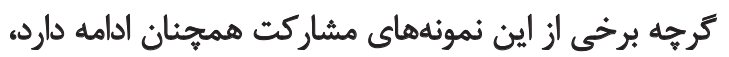

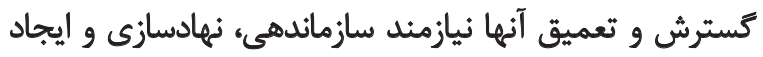

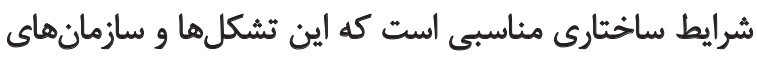

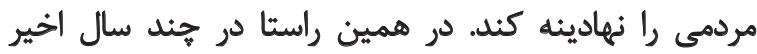

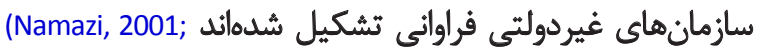
Behrang, Kazemiean, Norani Nezhad, Asardari, \& Mafi, 2013)

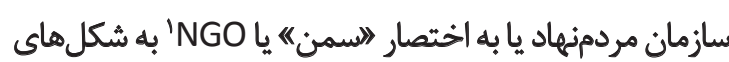

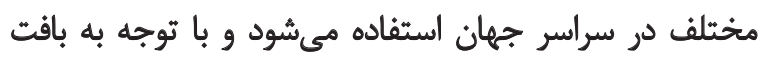

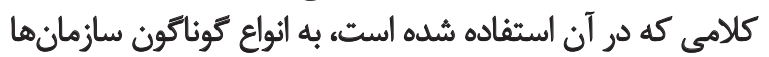

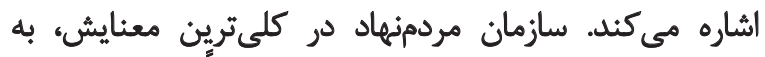

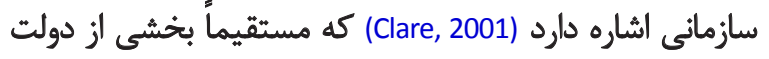

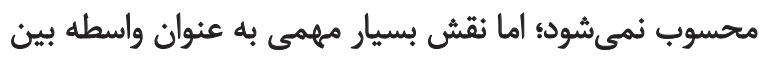

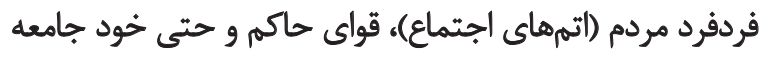
ايفا مى كند ائدم (Shahbahrami, Pishgahifar, Zalpoor, \& Bakhtiyari)

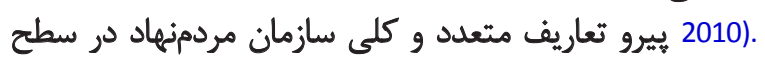

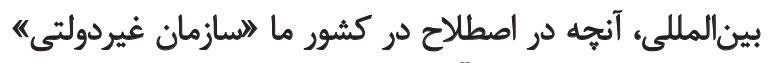

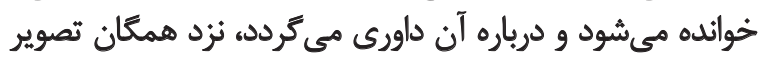

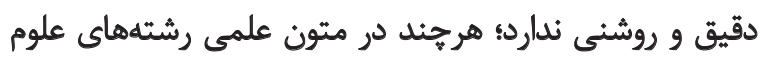

1. Non-Governmental Organization

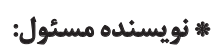

دكتر خديجه بوزرجميهرى

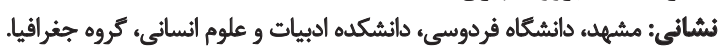

تلفن: azar@um.ac.ir يست الكترونيكي 
كه از سال IrAD در روستاهاي استان خراسان رضوى تشكيل

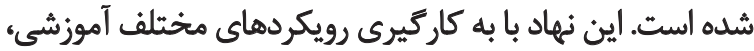

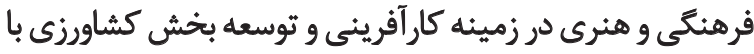
اهداف معين تشكيل شده است (Ministry of Agriculture, 2006)

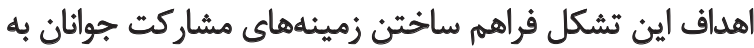

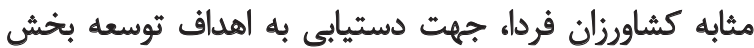

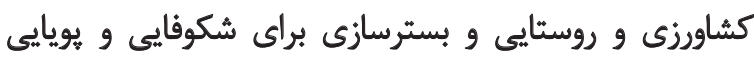

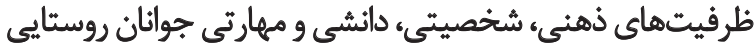

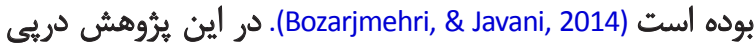

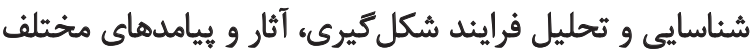
اين تشكل در منطقه موردمطالعه هستيم.

\section{مرورى ببر ادبيات موضوع}

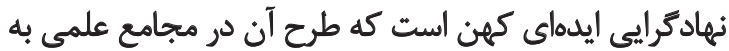

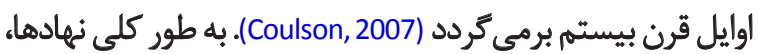

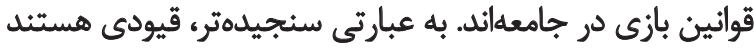
وضع شده از جانب نوع بشر كه روابط متقابل انسانها ران رابا با يكديكر شكل مي دهند (Roknodin Eftekhari, \& Badri, 2012).

نهاد و نظريه نهاد در علوم سياسى، جامعهشناسى، جغرافيا،

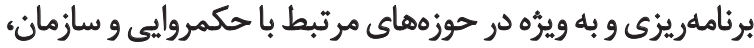

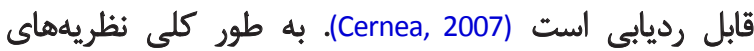

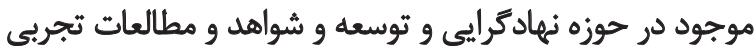

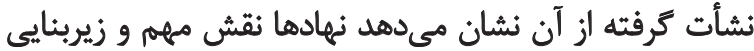

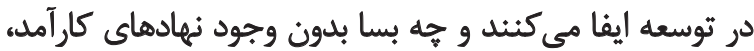

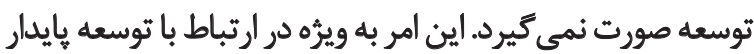

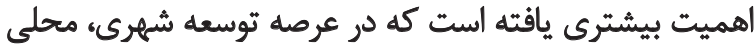

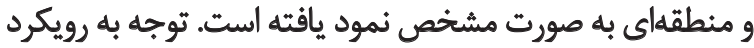

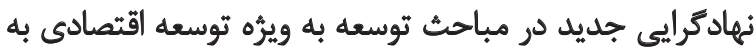

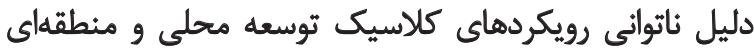

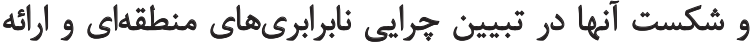

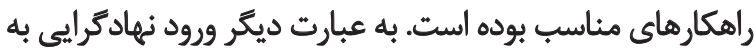

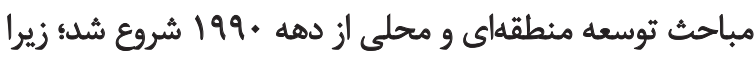

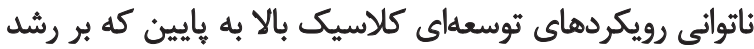

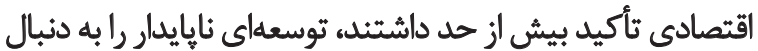
داشته است (Korten, 1990).

توسعه و تحول جوامع و همجنين فرايند جهانى سازى در قرن

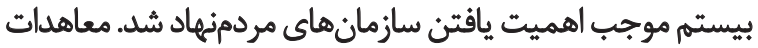

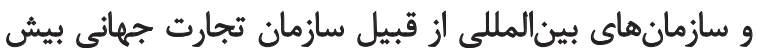

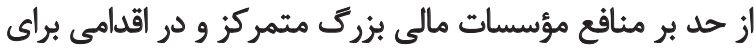

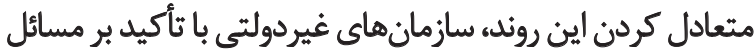

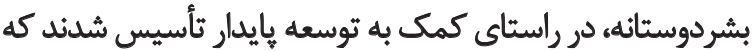
نمونه بارز آن اجلاس اجتماعى جهان است كه به هر ساله باله در ماه
سازمانهاي مردمزههاد، به طور كلى با تأكيد بر سه اصل داوطلبانه،

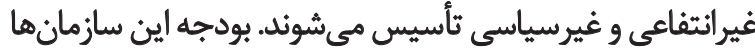

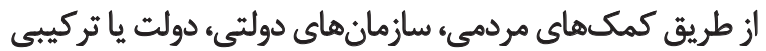

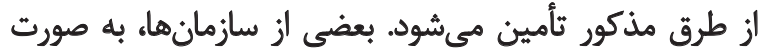

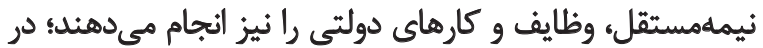

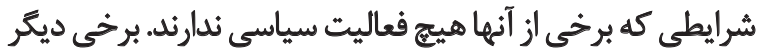

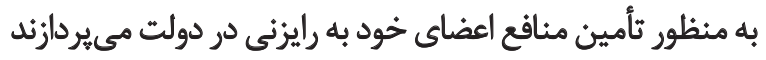

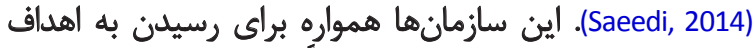

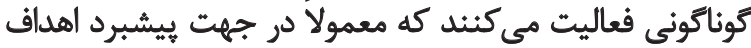

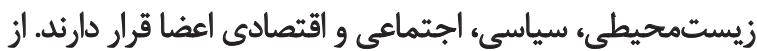

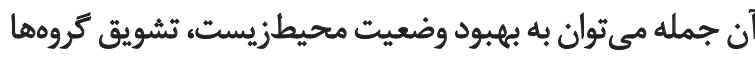

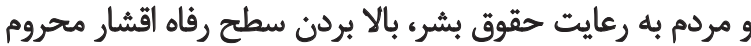

و آسيبيذير جامعه از جمله زنان اشاره كرد (Moghimi, 2004).

سازمانهاى غيردولتى را بر اساس معيارهاى توناكون از جمله

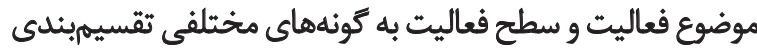

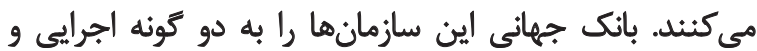

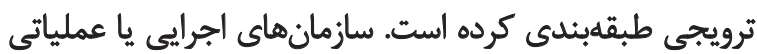

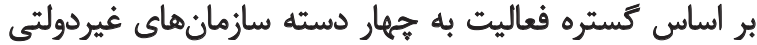

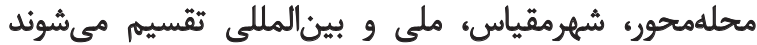

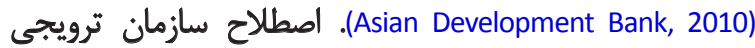

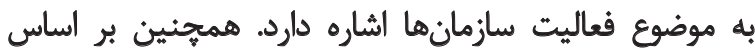

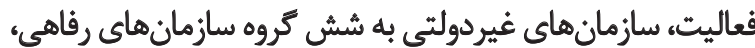

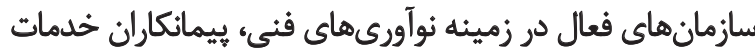

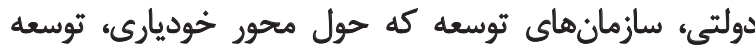

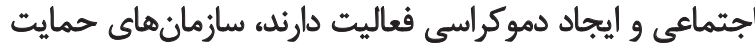

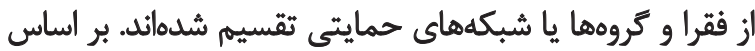

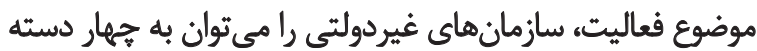

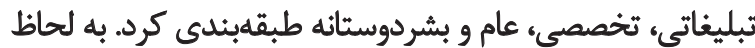

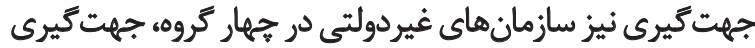

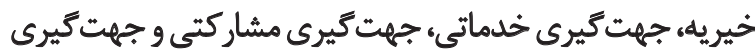

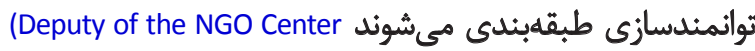
for Social and Cultural Affairs, Department of the Interior, 2011)

برخي تحقيقات نشان دادهاند سازمانهاى مردمنهاد فعال در

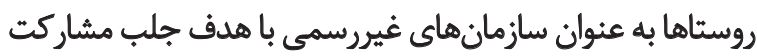

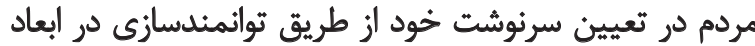

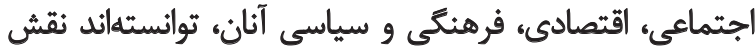

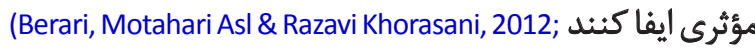
Abdolahi, 2008)

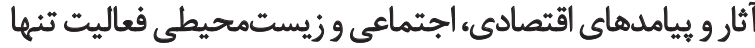

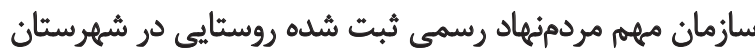

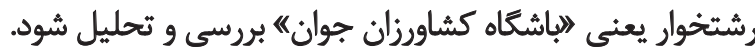

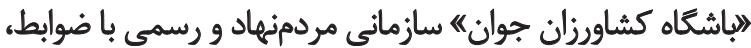

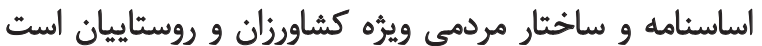




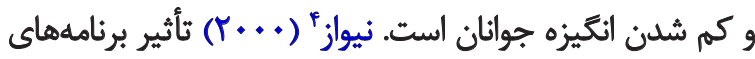

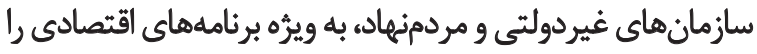

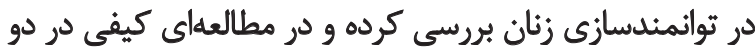

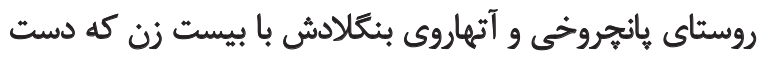

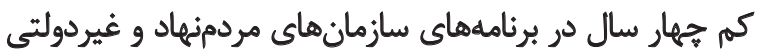

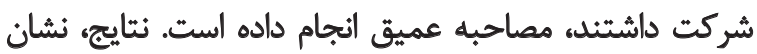

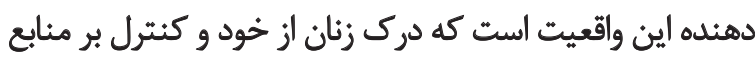

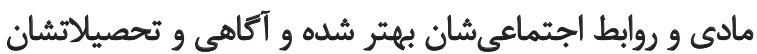

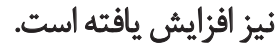

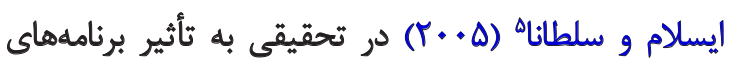

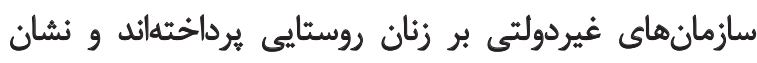

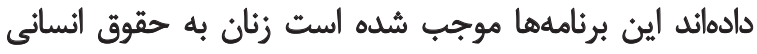

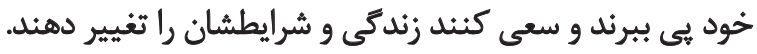

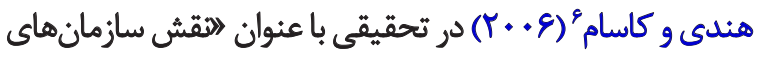

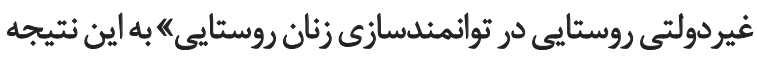

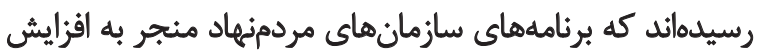

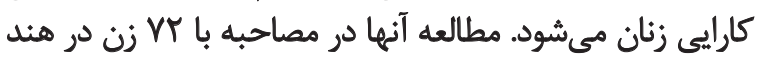

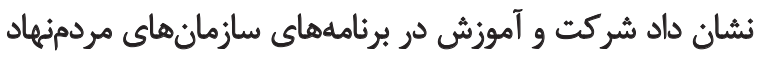

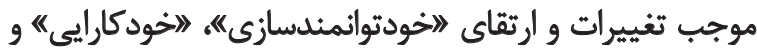
اخودبهينهسازى زنان" مى إشود.

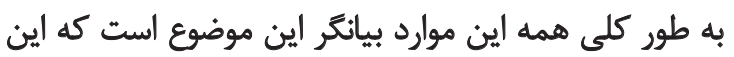

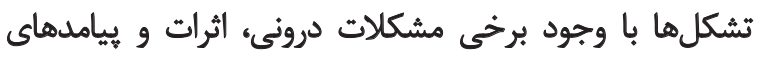

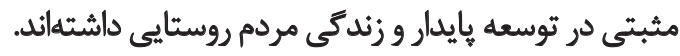

\section{روش شُشاسي تحقيث}

اين بثروهش از منظر بارادايم تحقيق، جزو تحقيقات كيفى

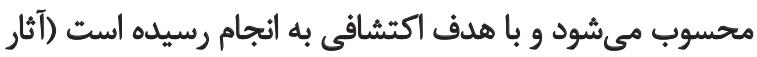

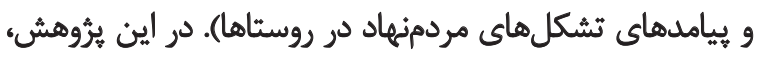

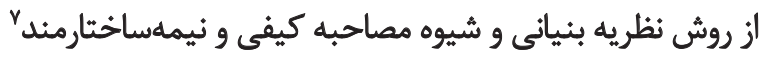

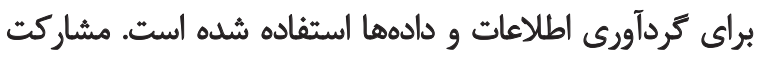

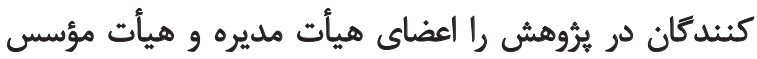

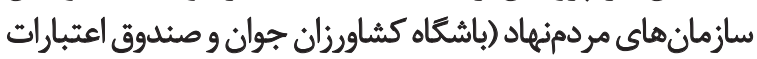

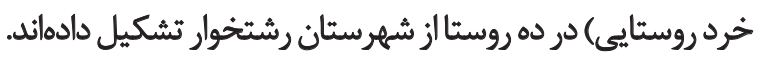

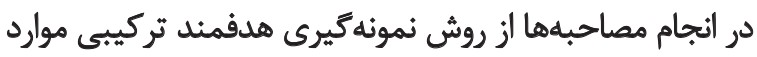

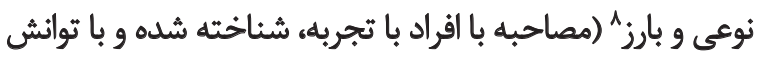

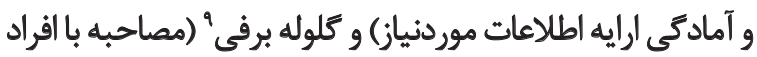

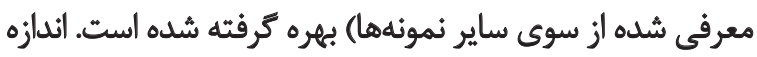

\section{Newaz}

5. Islam \& Sultana

6. Handy \& Kassam

7. Semi-structured deep interview

8. Typical cases

9. Snow balling
رأويه در شهر داووس ' سوئيس بركزار مىشود و رقيب اجلاس اقتصادى جهان است (Shakori, 2011).

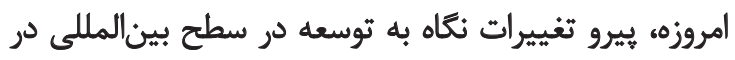

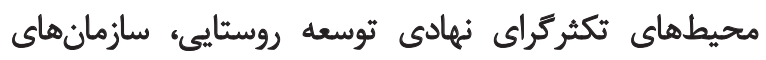

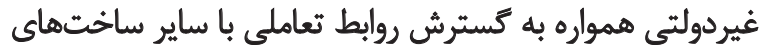

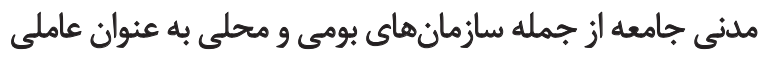
هايدار و سازئده توجه دارند.

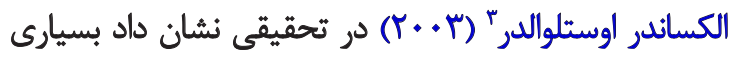

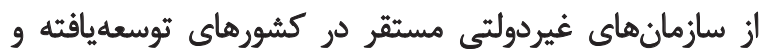

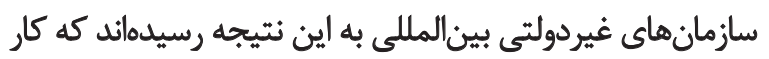

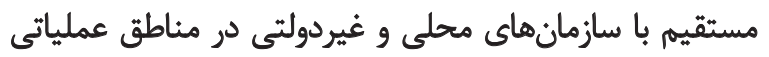

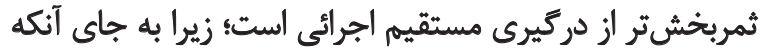

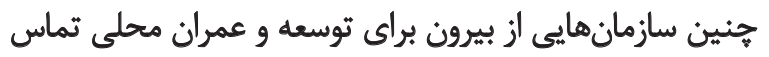

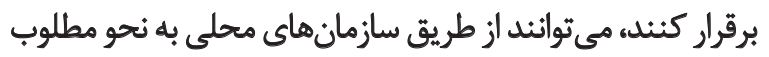

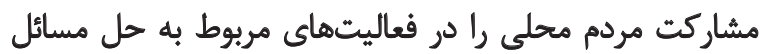

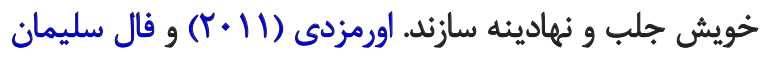

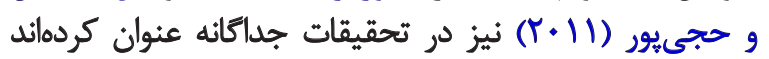

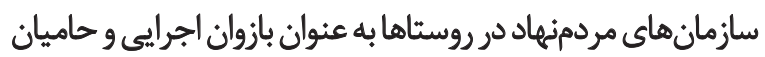

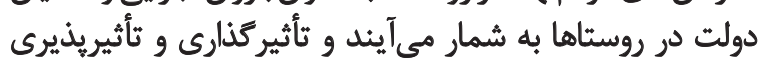

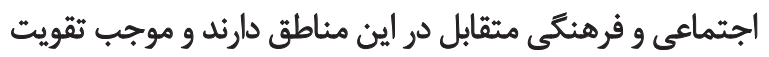

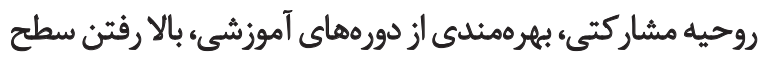

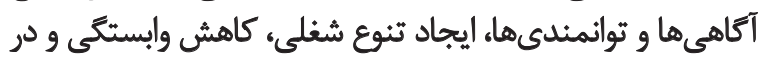

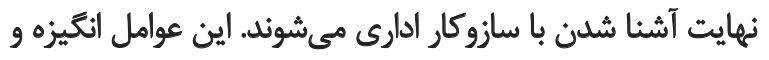

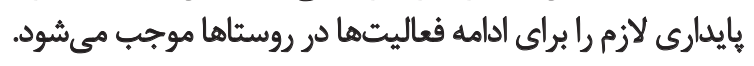
صبحى مقدم (Y.|F) در تحقيقى با عنوان السازمانهاي

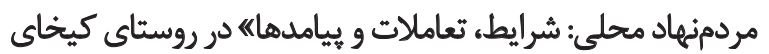

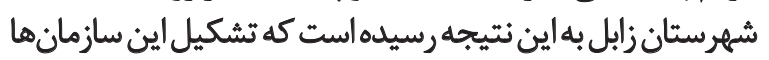

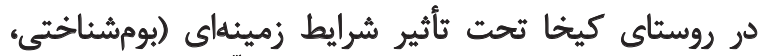

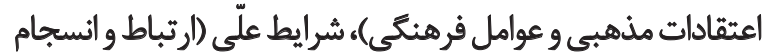

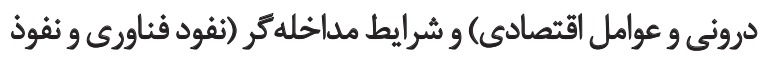

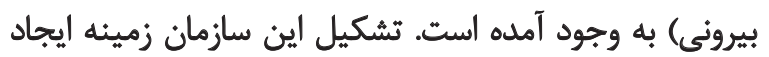

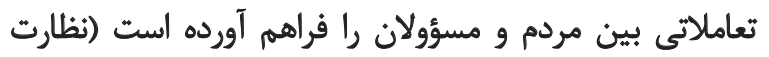

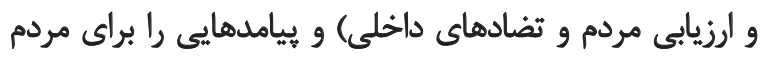

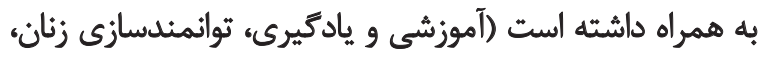

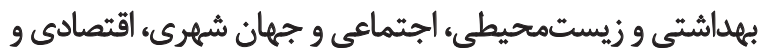

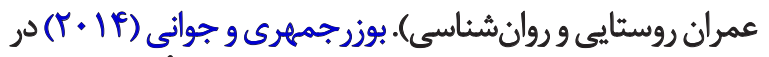

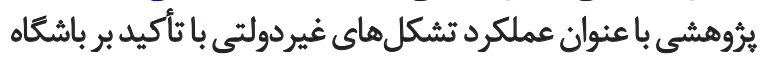

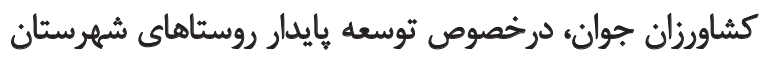

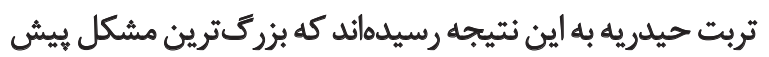

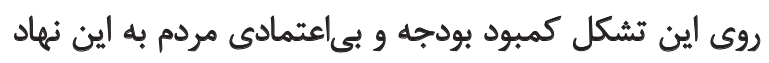

2. Davos

3. Alexander Osterwalder 


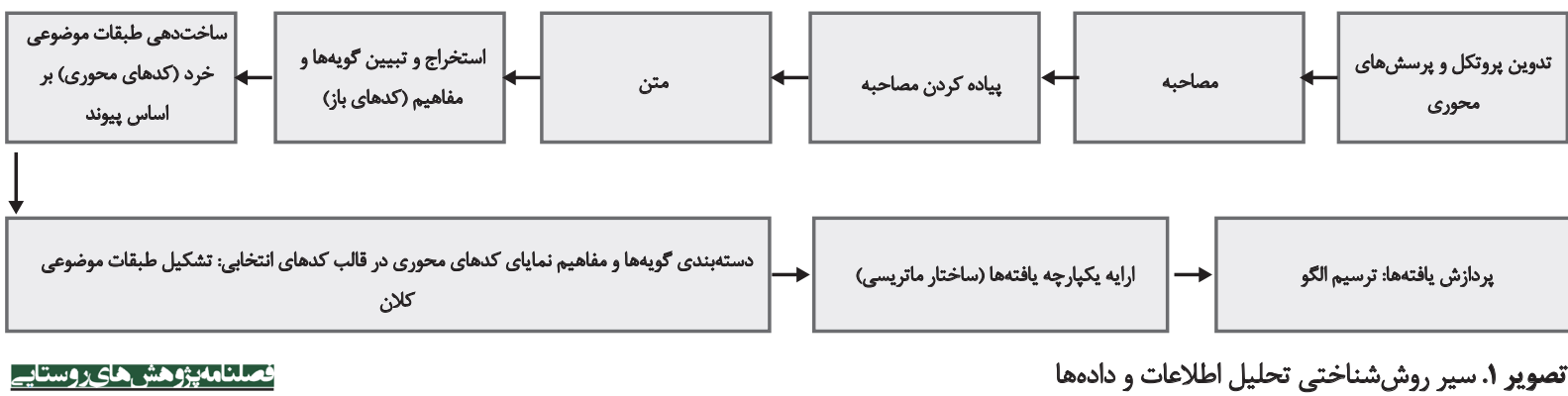

نزديكى برداشتهاى متقابل و واكويهسازى مضمونمدارئارئا

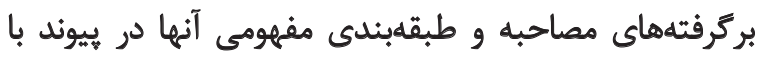

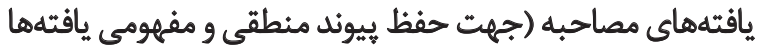
با دادهها و اطلاعات بركرفته از مصاحبه) اشاره نمود.

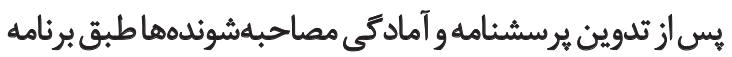

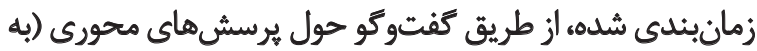

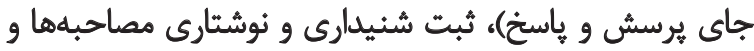

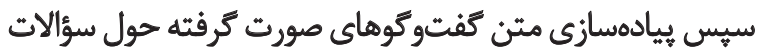

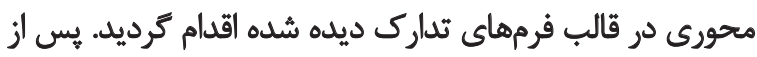

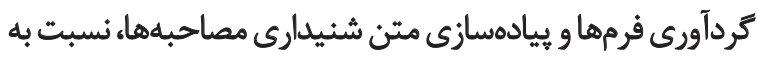
يإلايش، بازخوانى، دستهبندى و ارايه يافتهها اقدام شد.

يافتهها

در اين تحقيق، تحليل و ارايه يافتههاى حاصل از مصاحبهكرى

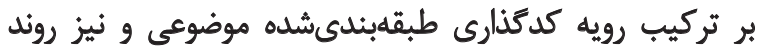

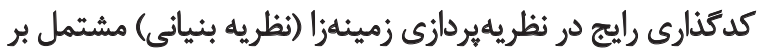

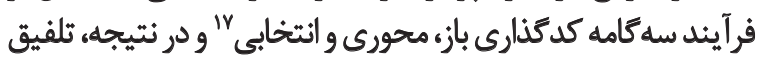

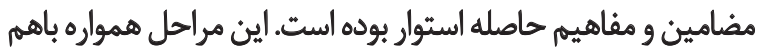

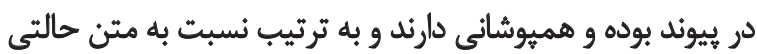

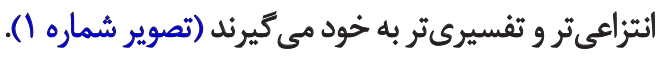

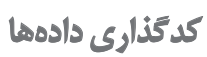

در جريان كد كذارى، برخى از كدها يا در واقع مضامين و مفاهيم،

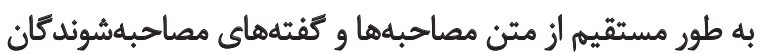

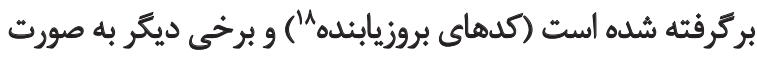

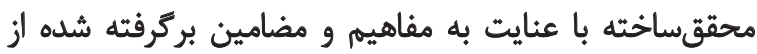

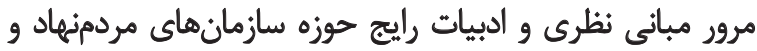

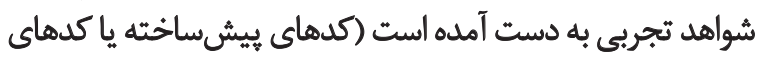

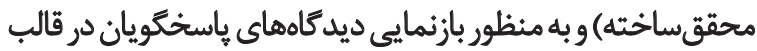

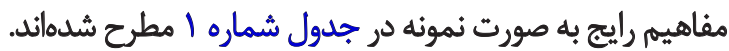

16. Thematic-based

17. Open coding, Axial coding and selective coding

18. Emerging codes
نمونه وفرايند كردآورى اطلاعات تا سطح اشباع نظرى " يا آستانه

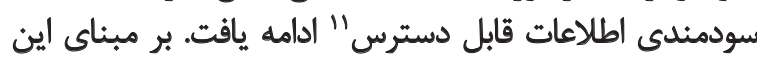

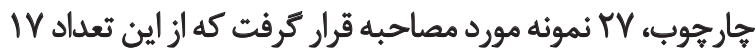

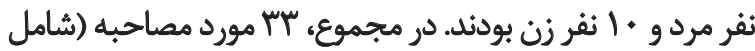

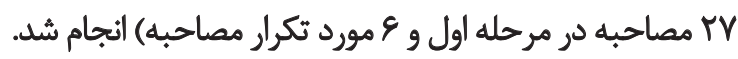

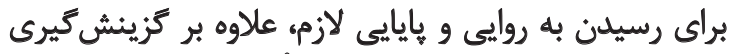

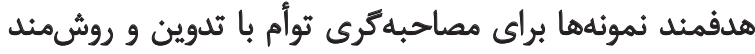

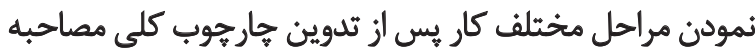

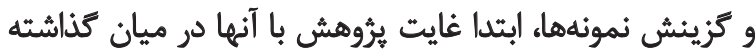

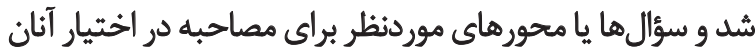

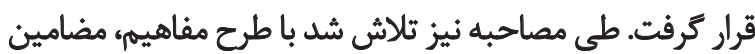

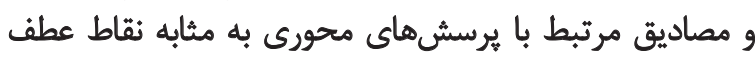

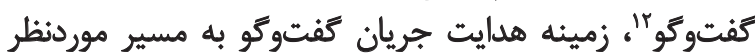

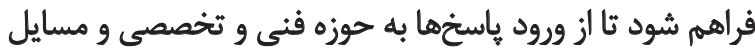

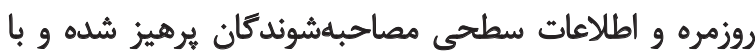

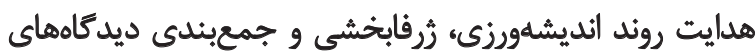

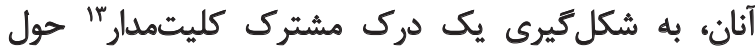
محورهاى مورد بحث كمك شود.

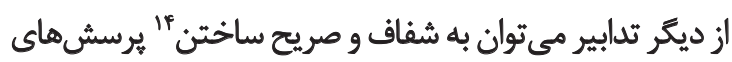

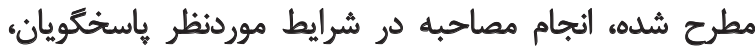

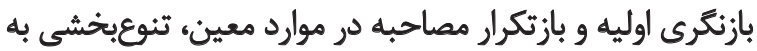

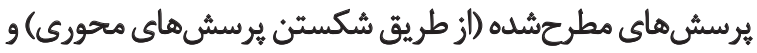

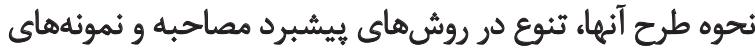

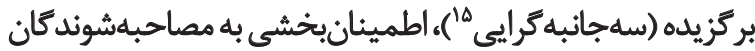

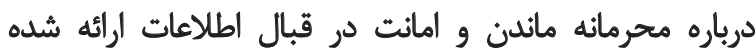

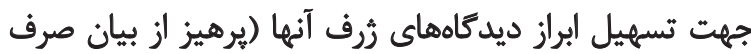

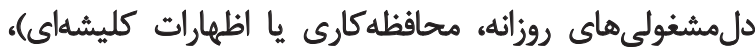

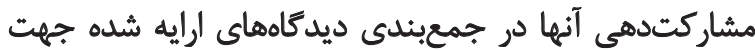

10. Theoretical saturation

11. Usefulness threshold of available information

12. Turning points of dialogue

13. Comprehensive common understanding

14. Crystallization

15. Triangulation 
جدول ا. بخشى نمونهوار از مرحله اول يردازش نتايج: تبديل متن مصاحبهها به كد

\begin{tabular}{|c|c|c|c|}
\hline كدهاي استخراج شده (كدهاى باز) & باسخ & مضمون يرسش & شونده \\
\hline 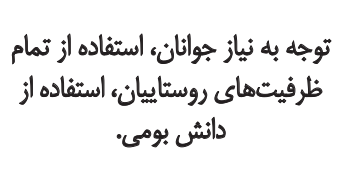 & 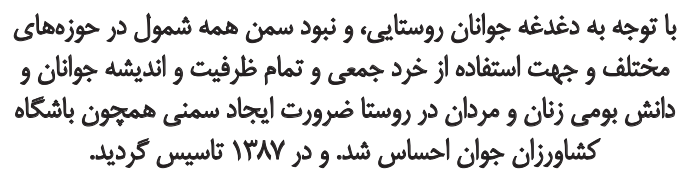 & كشاون ايجاد سمن (باشكاه در روستا & 1 \\
\hline 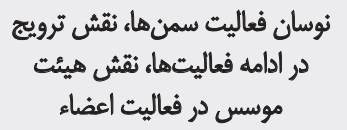 & 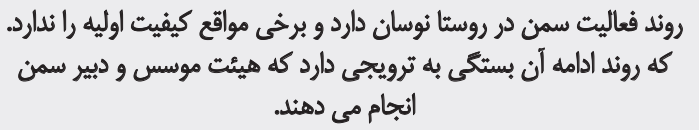 & 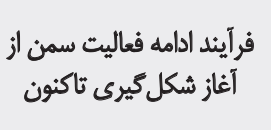 & $r$ \\
\hline
\end{tabular}

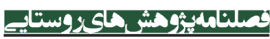

قابليت دارند. در واقع اكر كدهاى باز به مثابه مفاهيم و مضامين

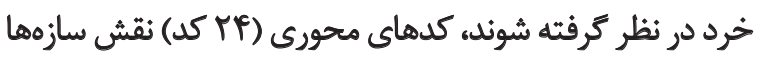

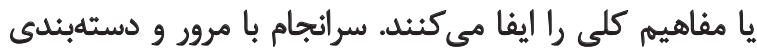

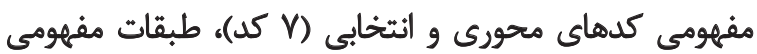

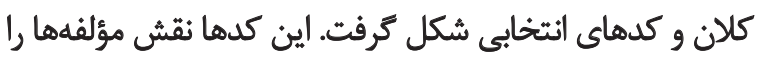

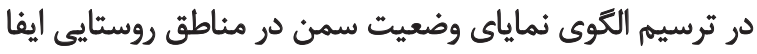

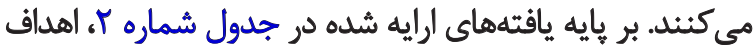

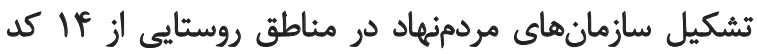

اهداف تشكيل سازٔمان مردمثيهاد

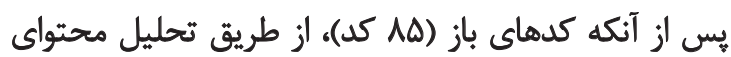

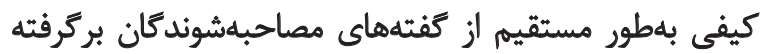

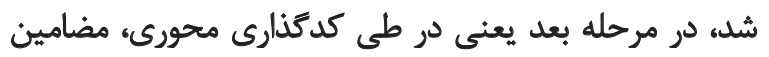

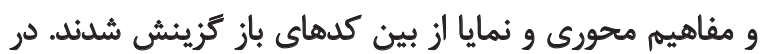

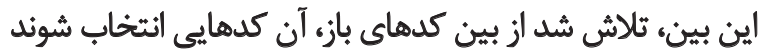

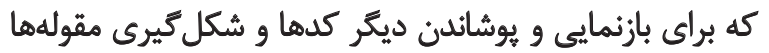

جدول r. ساختار ماتريسى يكيارجه تحليل دادها و اطلاعات طبقه كلان اهدف تشكيل سازمان مردم نهاد باشكَاه كشاورزان جوان

\begin{tabular}{|c|c|c|c|c|c|}
\hline (كدهاى انتخابى/ كزازارهها) & طبقه موضوعى خرد (كدهاى & 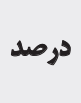 & فراواتى & كد & رديف \\
\hline \multirow{14}{*}{ اهداف تشكيل سازمان مردم } & \multirow{4}{*}{ استفاده از تمام ظطرفيتها } & r & $r$ & استفاده از دانش بوهى & 1 \\
\hline & & q4 & m & استفاده ازز تمام ظرفيتهايى روستاييان & r \\
\hline & & 91 & r. & استفاده از خرد جمعى & r \\
\hline & & fo & 10 & استفاده از توانايع زنان روستايع & f \\
\hline & \multirow{5}{*}{ افزايش همكارى و انسجام بين } & hr & If & تقسيم كار بين جوانان روستايى & $\Delta$ \\
\hline & & $r+$ & 1. & ايجاد كار تروهى & 8 \\
\hline & & fo & 10 & تعامل و همكارى & $\checkmark$ \\
\hline & & ve & ra & أنسجام فعاليت جوانان & $A$ \\
\hline & & Ar & tr & ايجاد روحيه نشاط در بين جواثان & 9 \\
\hline & \multirow{5}{*}{ مائدكارى جواثان در روستا } & १ท & $\pi$ & توجه به نياز جواثان & 1. \\
\hline & & Po & 10 & بروز رسانى اطلاعات و توانمندى جوانان روستايعي & 11 \\
\hline & & r* & 1. & راهكارهاى ير كردن اوقات فراغت جواثان & ir \\
\hline & & 91 & $r$ & هدف دادن جوانان در اشتغال زايع & $\mathbb{1}$ \\
\hline & & 8. & r. & هقابله با رووستا كريزى & if \\
\hline
\end{tabular}


جدول ؟. ساختار ماتريسى يكيارجه تحليل دادها و اطلاعات طبقه كلان نحوهُ عضو كيرى سمنها

\begin{tabular}{|c|c|c|c|c|c|}
\hline 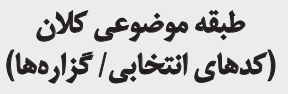 & (كدهاي محوريى خرى) & 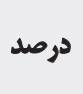 & فراوانى & كد & روريف \\
\hline \multirow{5}{*}{ نحوه عضو كيرى سمنها } & انواع تبليغات جهت & $1 .$. & $m$ & 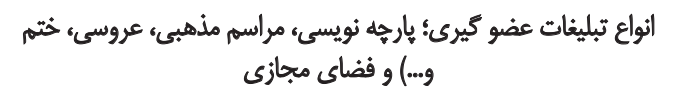 & 1 \\
\hline & عضوكيرى & q. & $r+$ & عضوكيرى خود جوش با فعاليت اعضاى اصلى & r \\
\hline & & $1 .+$ & r & علم ابطال كارت عضويت حتى با مهاجرت ازز روستا & r \\
\hline & و روستائيان مر عضوديت & $1 .$. & m & 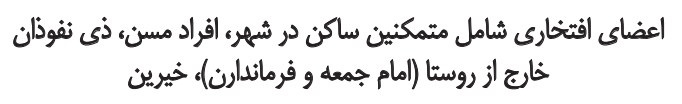 & f \\
\hline & & \&s & rr & ايجاد هويت در روستاييان جهت انكيزه و عضويت اعضا & $\Delta$ \\
\hline
\end{tabular}

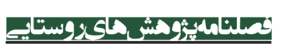

\section{نحوه عضوكَيرى سازمان مر دمنهاد}

نحوه عضوكيرى سمنها در روستاهاى منطقه، به عنوان

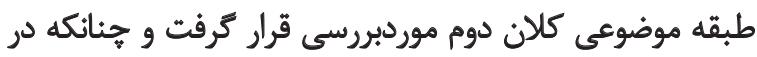

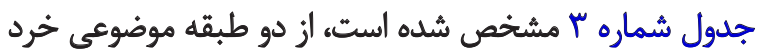
الانواع تبليغات جهت عضوكيرى شو و العدم محدوديت روستاييان

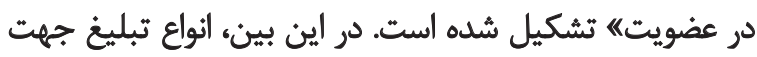

باركذارى شده به سه طبقه موضوعي خرد يا كد محورى شامل:

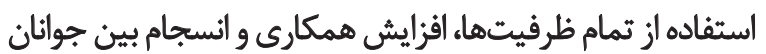

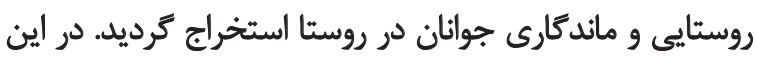

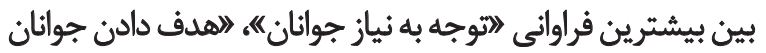

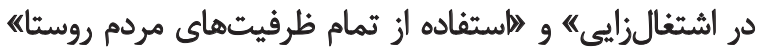

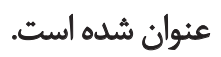

جدول P. ساختّار مائريسي يكيارجه تحليل دادهها و اطلاعات طبقه كلان عوامل ادامه روند فُعاليت سمن در روستا

\begin{tabular}{|c|c|c|c|c|c|}
\hline 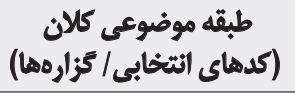 & (كدهاي محوريى خرى) & موصد & فراواتى & كد & رديف \\
\hline \multirow{13}{*}{ عوامل ادامه روندفعاليت سمن } & \multirow{5}{*}{ نقش هيُتَ هونس و اعضاى } & $1 .$. & 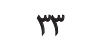 & عدم محدوديت اعضاى اصلى & 1 \\
\hline & & 1.0 & r & نقش هيئت موسس در فعاليت اعضاء & r \\
\hline & & $M$ & rq & عملياتى نمودن برنامه ها توسط اعضاى اصلى & r \\
\hline & & 91 & r. & فعاليت هيئت موسس و اعضاى اصلى نر ايجاد انكيزها اعضاء & f \\
\hline & & 91 & ५* & ترويج هيُتَ موسس عامل انكيزه اعضا & $\Delta$ \\
\hline & \multirow{4}{*}{ ايله جديد در فعاليت } & $\Lambda \Delta$ & rA & يرخوردارى از ايله جديد & 8 \\
\hline & & AT & rr & به روز بودن همراه با بومي كردن برنامه هـا & $\checkmark$ \\
\hline & & \&) & r. & علم روزمركى و كهنكى برنامههاى سمن & $\wedge$ \\
\hline & & 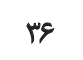 & ir & نقش ثرويج در ادامه فعاليتها & 9 \\
\hline & \multirow{3}{*}{ درئر كردن همه اعضاى سمن } & r & $\checkmark$ & 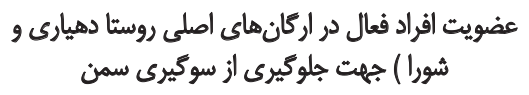 & 1. \\
\hline & & 81 & r. & مركير كردن همه اعضا & 11 \\
\hline & & ra & re & نظر خواهى از همه اعضا & ir \\
\hline & ايجاد برنامه شاى شاد جهت & 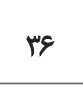 & ir & 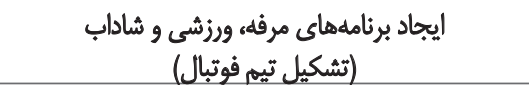 & ir \\
\hline
\end{tabular}


در فعاليت سمن است. از بين كدهاي باركذارى شده در اين طبقه

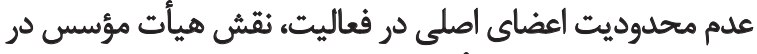

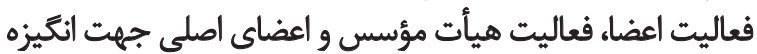

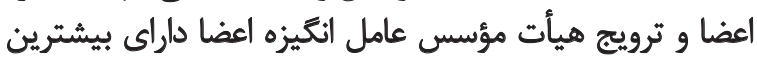

فراوانى هستند كه در جدول شماره f مشخص شده است.

$$
\text { آثار و يبامدهاى اقتصادى سازمان }
$$

آثار و ييامدهاى اقتصادى سازمانهاى مردمنهنهاد به عنوان ديكر

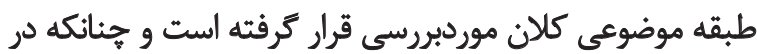

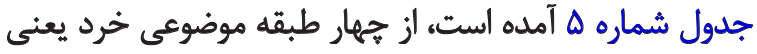

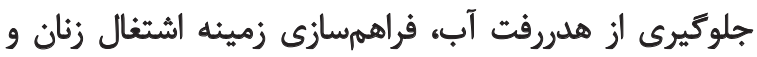

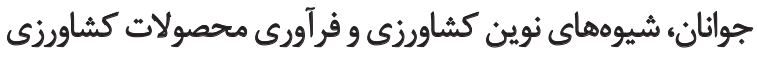

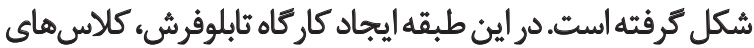

عضوكيرى، عدم ابطال كارت عضويت حتى با مهاجرت أز روستا

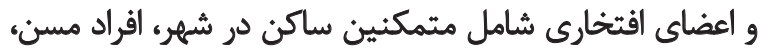

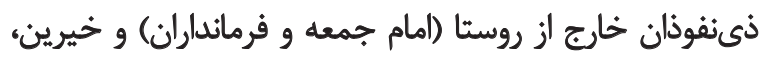

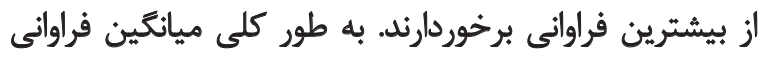

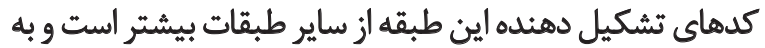

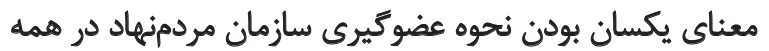

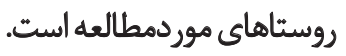

روند فعاليت ساؤمان مردمنههاد از ديخر طبقات موضوعى كلان موردبررسى، عوامل ادامه روند

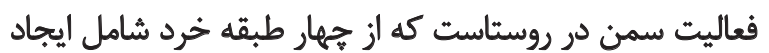

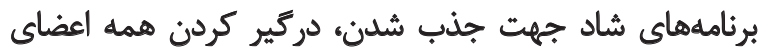

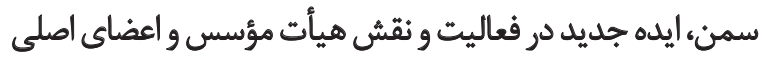

جدول ه. ساختار ماتريسى يكيارجه تحليل دادهها و اطلاعات طبقه كلان آثار و بيامدهاي اقتصادى

\begin{tabular}{|c|c|c|c|c|c|}
\hline (كدهاى انتخابى / كزارهـان) & (كبقه موضوعى خرى محرد) & 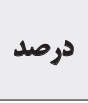 & 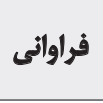 & كد & رديف \\
\hline & & צ & ir & يكيارجه سازى اراضى روستايى & 1 \\
\hline & & rq & ir & تجميع منابع آب & r \\
\hline & جلوكيرى از هلدر رق اب & v. & r & جلوكيرى أز هلر رفت آب با شيوههاى نويين آب يارى & r \\
\hline & & $\Lambda$ & ru & حدف كثت برخى از اقلام ير مصرف آب (جغنلدر) & $r$ \\
\hline & & 91 & r. & 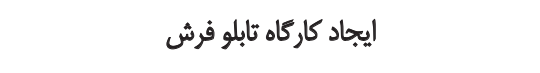 & $\Delta$ \\
\hline & & 91 & r. & أموزش كلاسهاى خياطى و كلدوزى & 8 \\
\hline & أشئال زنمان و جوازئان زمينه & ve & ra & آموزش يرورش زنيور عسل & $\checkmark$ \\
\hline & & 99 & r & حضور زنان در كار كاههائ خائكى هم زمان با حضور در خانه & $\wedge$ \\
\hline & & er & rr & كار كاه يرورش قارج & 9 \\
\hline \multirow[t]{10}{*}{ آثار و ييامدهاى اقتصادى } & & 81 & r. & أموزش شيوههاى نويين كشاورزى & 1. \\
\hline & & 91 & r. & بالا بردن سطع زير كشت زعفران & 11 \\
\hline & 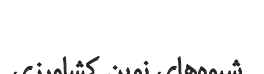 & rr & if & الحداث كلخانه & ir \\
\hline & 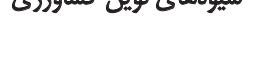 & r & r & احداث مزرعه الكو بسته & r \\
\hline & & Po & 18 & الحداث مزرعه الكو زعقران & if \\
\hline & & ra & 10 & أموزش يرواربندى صنعتى كوسفثل & 10 \\
\hline & & $\Delta \Delta$ & M & بستهبثدى زعفران & is \\
\hline & فرأورى محصولات & re & ir & 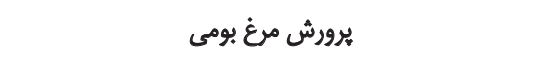 & iv \\
\hline & كشاورزى & r. & 1. & بستهبندى تخدم مرغ & M \\
\hline & & $r+$ & 1. & ايجاد و آموزش كارثاه ورمى كميوست & 19 \\
\hline
\end{tabular}




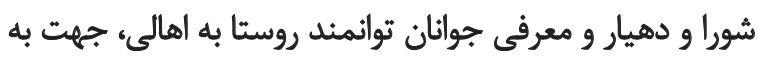

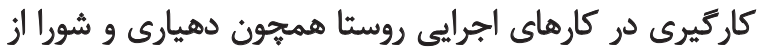
بيشترين فراوانى برخور دارند.

$$
\text { آثار محيطز يستى سازمان }
$$

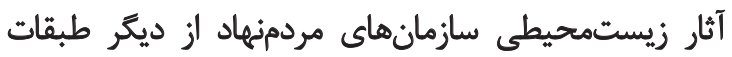

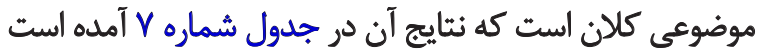

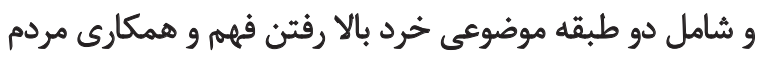

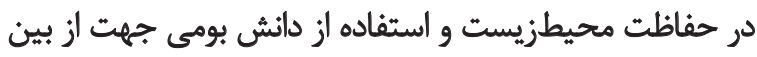

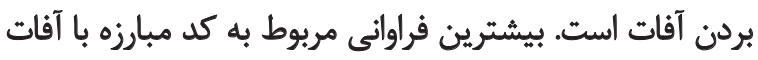

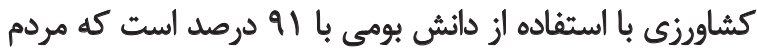

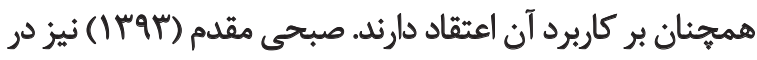

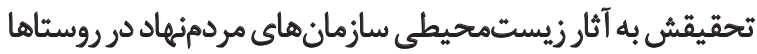

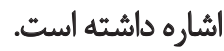

آهوزش خياطى و كلدوزى و بالا بردن سطح زير كشت زعفران

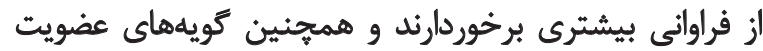

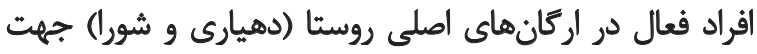

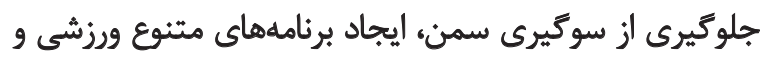

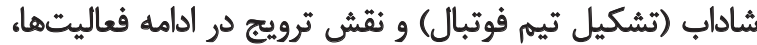

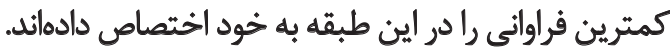

$$
\text { آثار و يبيامدهاى اجثماعى سازٔمان }
$$

همان طور كه در جدول شماره 9 مشاهده مىشود، طبقه

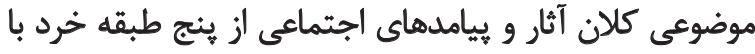

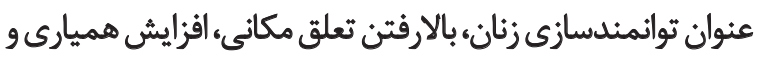

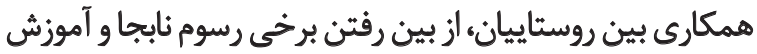

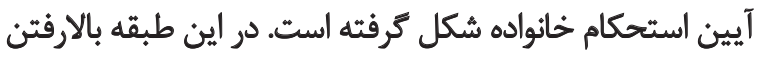

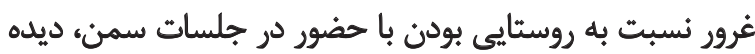

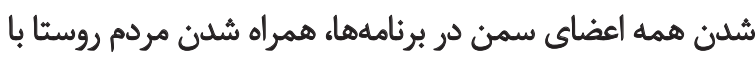

جدول \&. ساختار ماتريسى يكيارجه تحليل دادهها و اطلاعات طبقه كلان آثار و ويامدهاي اجتماعى

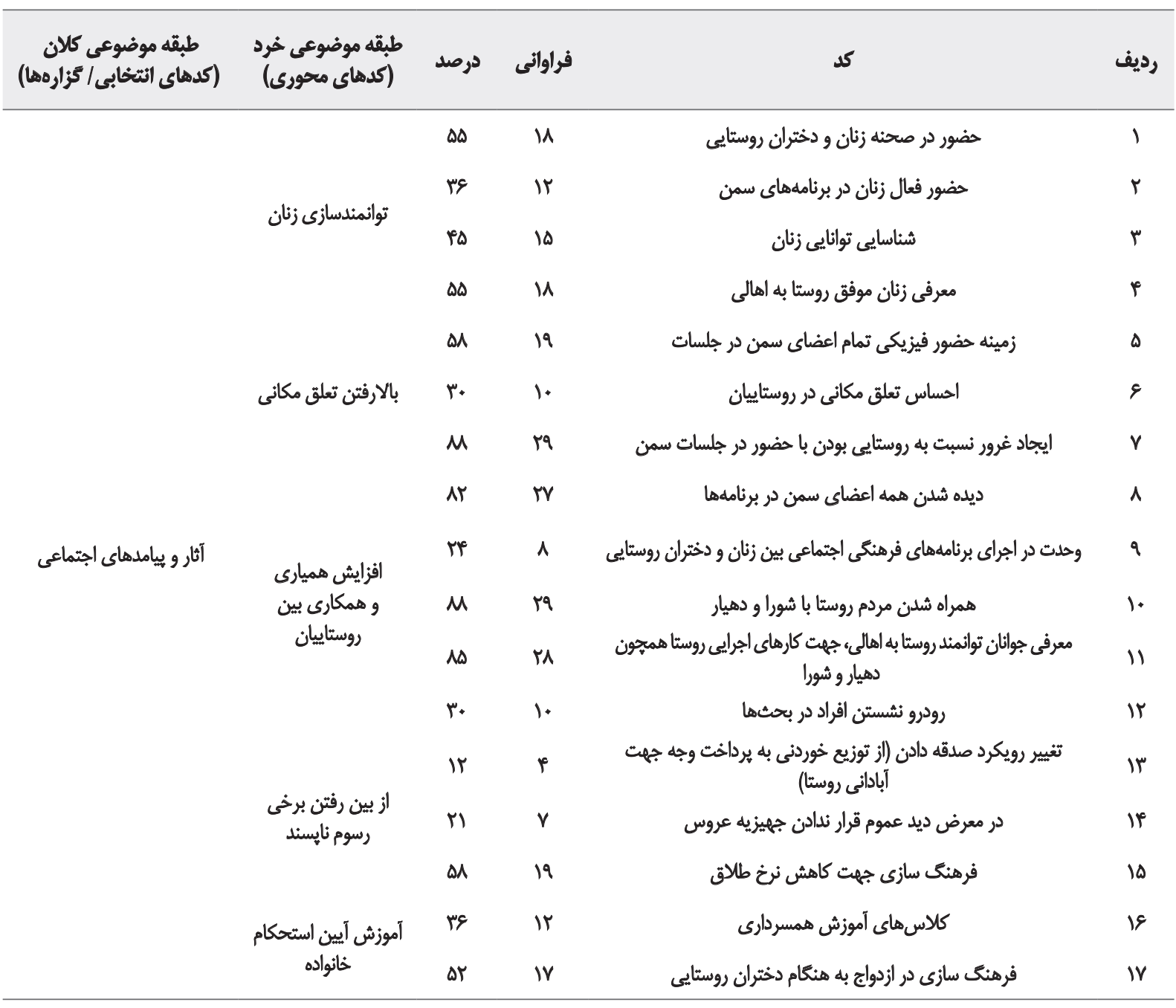


جدول V. ساختار ماتريسى يكيارجه تحليل دادهها و اطلاعات طبقه كلان آثار زيستمحيطى

\begin{tabular}{|c|c|c|c|c|c|}
\hline 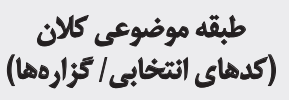 & طبقه موضوعى خرحد & دوصد & فراواتى & كد & رديف \\
\hline \multirow{4}{*}{ آثار زيست محيطى } & استفاده از دانش بومى جهت & 91 & r. & مبارزه با آفات كشاورزى با استفاده ازز دانش بومى & 1 \\
\hline & از بين بردن أقات & 81 & r. & از يين بردن آفات نباتى محصولات با ايجاد استخر & r \\
\hline & بالا رقتن فهم و همكارى محاظط محيط & is & is & يذيرش برنامههاى حفاظت از محيط زيست توسط اهالى & $r$ \\
\hline & 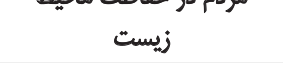 & ir & f & همليلى مردم در برنامههاي زيست هحيطي & p \\
\hline
\end{tabular}

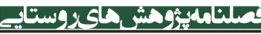

\section{بحث ونتيجه}

به منظور الكوسازى مفهومي يافتهاها، به استخراج مفاهيم

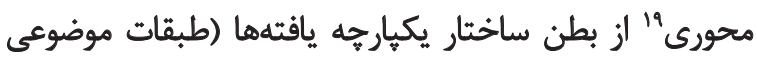

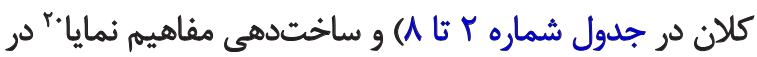

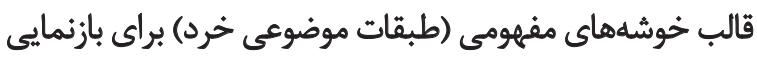

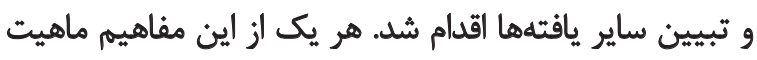

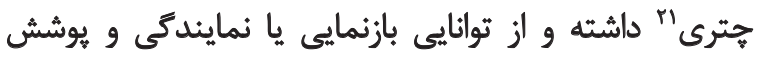

19. Axial concepts

20. Reprehensive concepts

21. Umbrella concepts
بروسي مشكالات ساومان

سرانجام آخرين طبقه موضوعي كلان با عنوان مشكلات

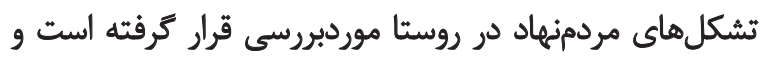

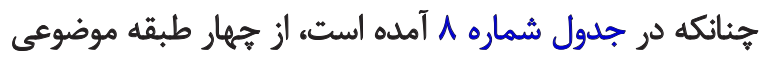

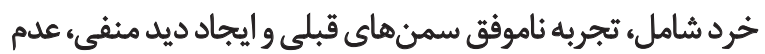

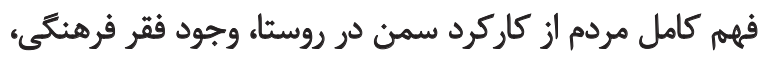

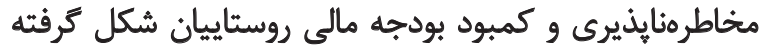

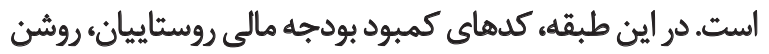

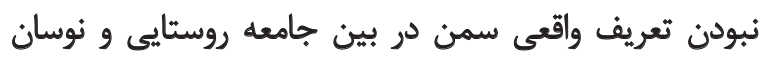

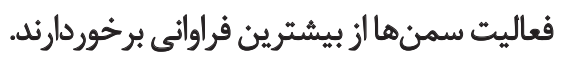

جدول A. ساختّار ماتريسي يكيارجه تحليل دادهها و مشكلات سازمان

\begin{tabular}{|c|c|c|c|c|c|}
\hline 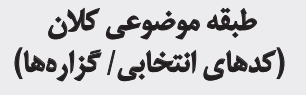 & (كدهاى محورى موضرد & درصد & فراوانى & 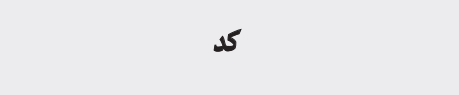 & رديف \\
\hline \multirow{8}{*}{ مشكات تشكل هاى مردم نهاد } & تجربه ناموفق سمن هاي قبلى و & r) & $\checkmark$ & بلديينى اعضا و مردم با ناموفق بودن برخى ازيل همجيون ثعاونى & 1 \\
\hline & إيجاد ديد منقى & ve & ro & نوسان فعاليت سمنها & r \\
\hline & عدم فهمه كاعل مردم از كاركرد سمن & re & ir & 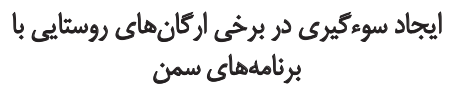 & $r$ \\
\hline & 䧑 & $\Delta \wedge$ & 19 & روشن ديودن تعريف واقعى سمن در بين جامعه & f \\
\hline & وجود فَقر فرهنكي & ar & iv & 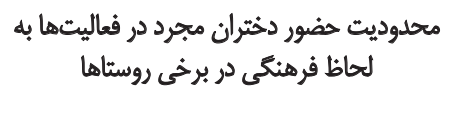 & $\Delta$ \\
\hline & & re & ir & عدم ثبول برنامههاي عنوان شده زنان توسط & 8 \\
\hline & علم ريسك يذيرى و كمبود بودجه & re & $\wedge$ & عدم ريسكيذيرى روستاييان & $\checkmark$ \\
\hline & مالى روستاييان & 10 & ru & كمبود بودجه مالى & $\wedge$ \\
\hline
\end{tabular}




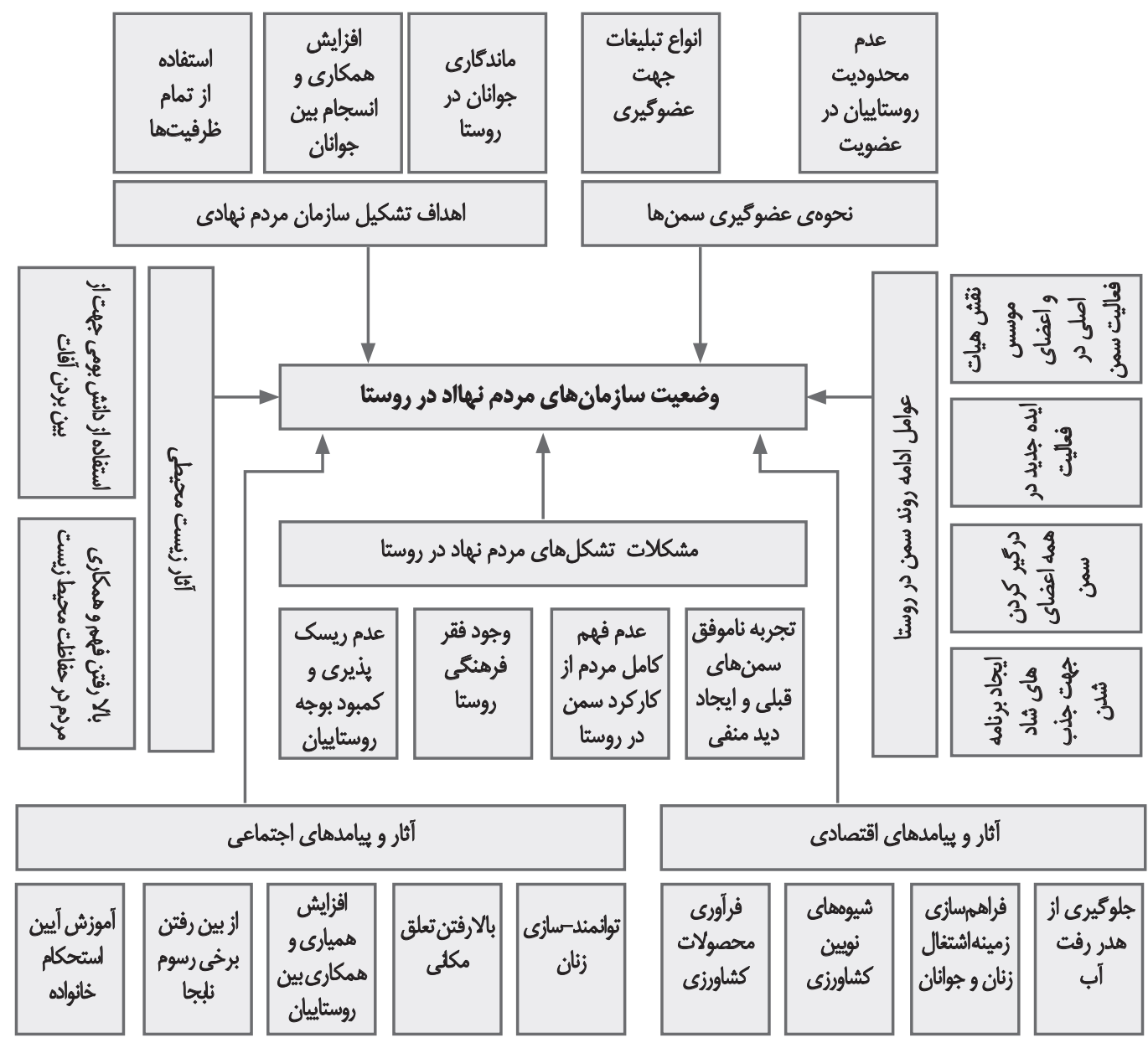

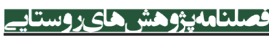

تصوير T. اللوى وضعيث سازمانهاي مردم نهاد در مناطق روسثايي

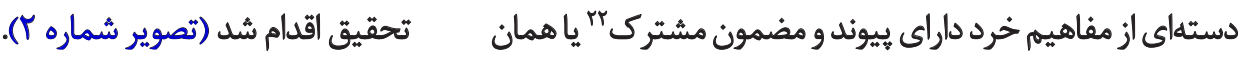

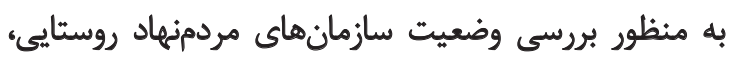

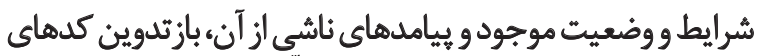

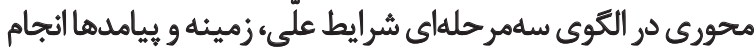

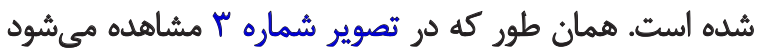

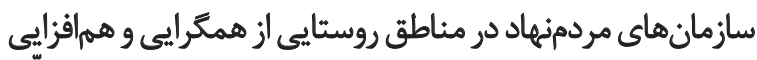
نظامهاى مختلف در يك بستر معين با اهدافى و شرايط علّى

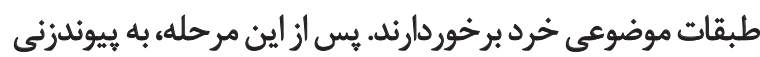

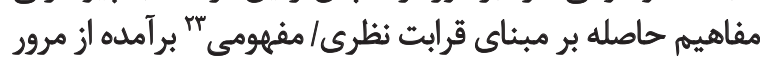

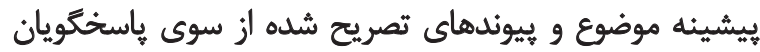

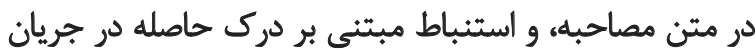

22. Thematic communality

23. Theoretical/conceptual proximity

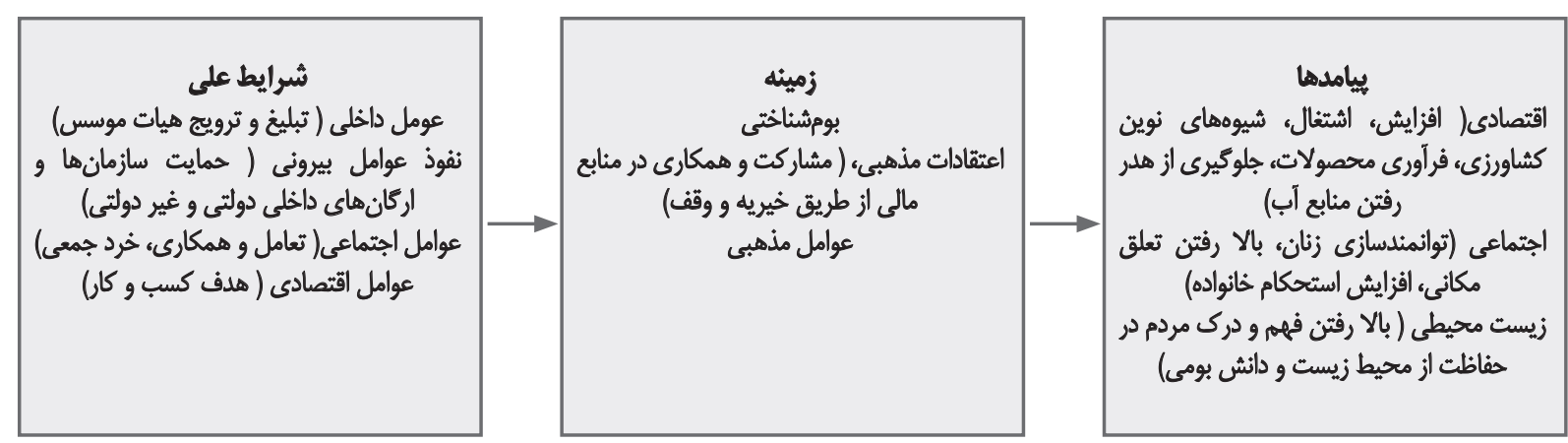




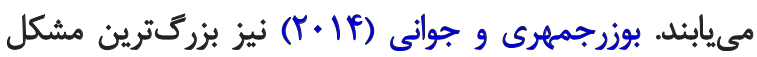

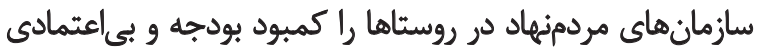

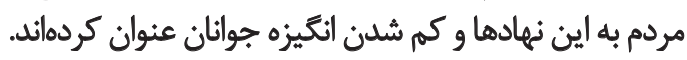

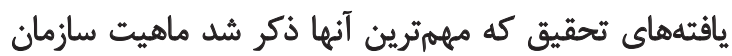

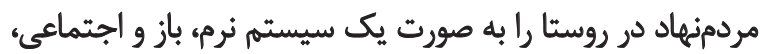

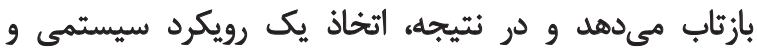

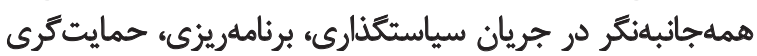

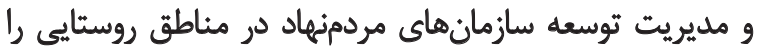

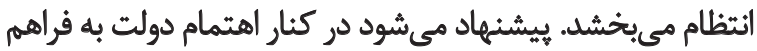

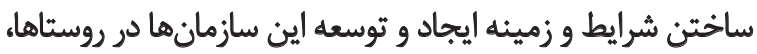

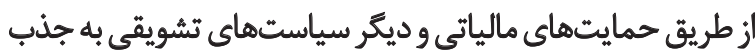

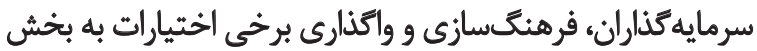

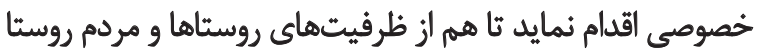

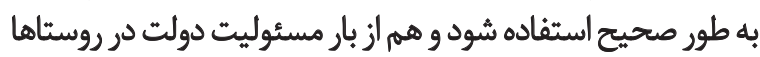

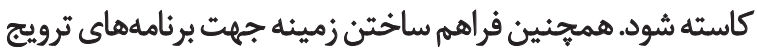

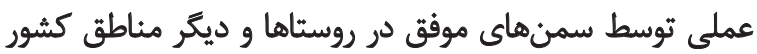

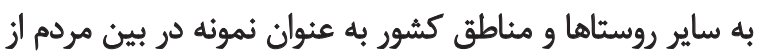

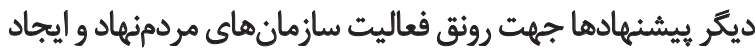
تعريف درست از سازمان مردمنهاد در بين مردم است.

$$
\text { تشكو و قدردانى }
$$

اين مقاله اززتتايج ميدائى رساله دكتراى خانم خديجه جواني در كروه جغرافياى دانشكاه فردوسى مشهد كرفته شده است.

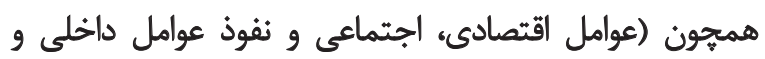

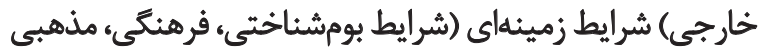

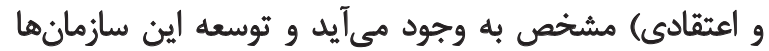

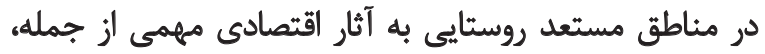

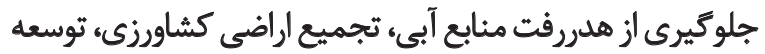

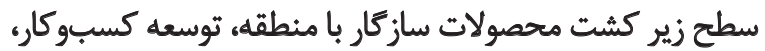

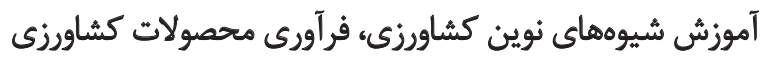

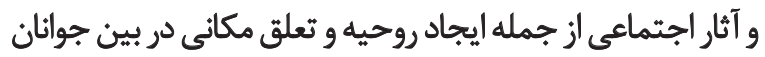

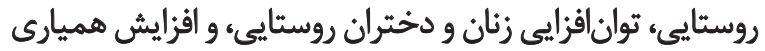

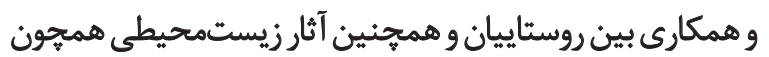

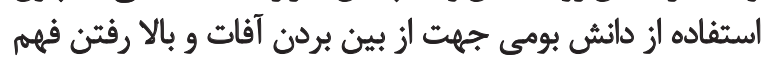

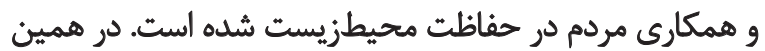

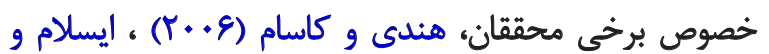

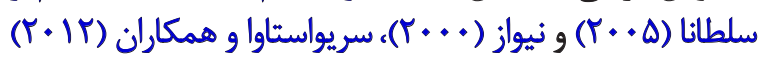

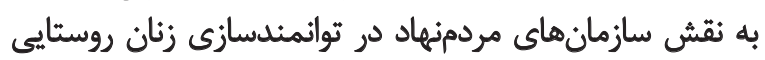

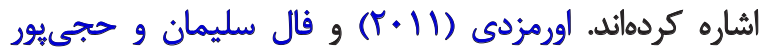

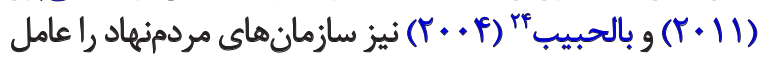

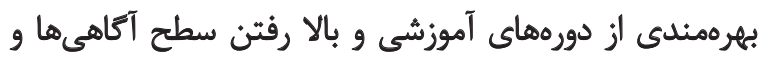
توانمندى هاى و ايجاد تنوع شغلى روستاييان دانستهاند.

به طور كلى يافتههاى اين تحقيق نشاندهنده تعدد ابعاد و و

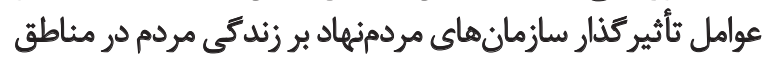

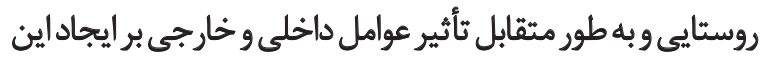

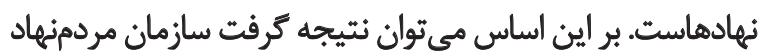

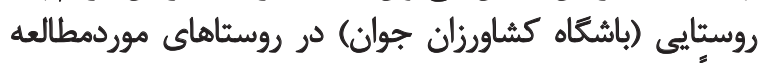

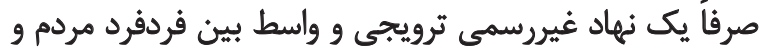

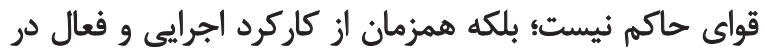

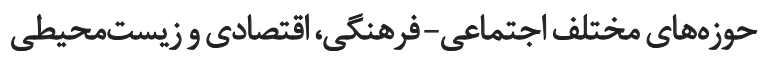

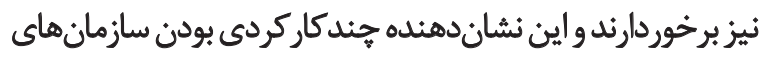

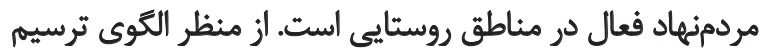

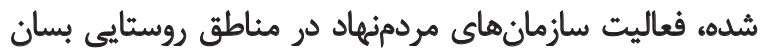

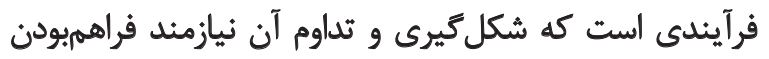

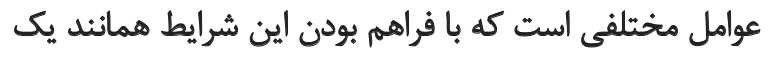

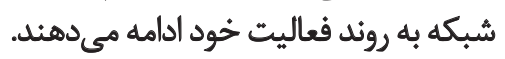
همان طور كه در التوّى يارادايمى (تصوير شماره بَ) و نيز تصوير

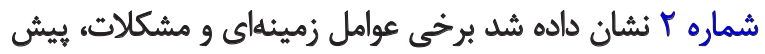

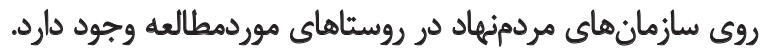

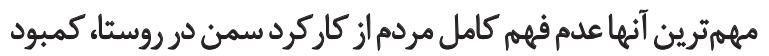

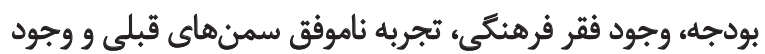

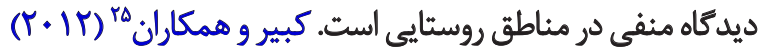

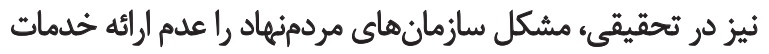

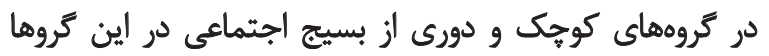




\section{References}

Abdolahi, M. (2008). [Women in the public sphere: Factors, obstacles and strategies for civic participation of Iranian women (Persian)]. Tehran: Jame'e Shenasan.

Asian Development Bank. (2010). Special evaluation study of the role of non-governmental organisations and community, Based organisations in Asian development bank projects. Mandaluyong: Asian Development Bank.

Behrang, K., Kazemiean, M., Norani Nezhad, H., Asardari, M. R., \& Mafi, H. (2013). [Database NGOs (Persian)]. Tehran: Arseh-e Sevom.

Belhabib, S. (2004). Moroccan women NGO: Civil society agents of change. Paper presented at The $3^{\text {rd }}$ ALWF Annual Conference of Women in the Arab World, Partners in the Community and on the World Stage, The League of Arab States Cairo, Egypt, 6-9 June 2004.

Berari, M., Motahari Asl, M., \& Razavi Khorasani, J. (2012). [Effect of non-governmental organizations on the social - economic female-headed households (Persian)]. Journal of Woman and Society, 3(1):153-76.

Bozarjmehri, Kh., \& Javani, Kh. (2014). [The performance of NGOs on sustainable development with an emphasis on young farmers club villages city of Torbat (Persian)]. Paper presented at The National Conference of Modern Topic in Agriculture, Tehran, Iran, 21 May 2014.

Brown, L. D. (1992). Nongovermental organization as development catalysts. Vienna: United Nations Industrial Development Organization.

Cernea, M. (2007). Non-governmental organizations and local development. Washington, D.C: The World Bank.

Clare, O. F. (2001). Rural development and sustainable livelihoods. Rome: Preface of Farming Systems and Poverty.

Coulson, A. (2007). Local government in eastern Europe: Establishing democracy at the grass roots. Cheltenham: Edward Elgar Publishing

Deputy of the NGO Center for Social and Cultural Affairs, Department of the Interior. (2011). [Introduction to principles, rules and regulations NGOs (Persian)]. Tehran: Ministry of Interior.

Falsoleyman, M., \& Hajipoor, M. (2011). [Analysis of the stability of NGOs in rural areas experience of international Carbon sequestration project in South Khorasan province (Persian)]. Journal of Applied Research in Geographical Sciences, 20(23), 107-27.

Handy, F., \& Kassam, M. (2006). Practice what you preach? The role of rural NGOs in women's empowerment. Journal of Community Practice, 14(3), 69-91. doi: 10.1300/j125v14n03_05

Islam, N., \& Sultana, N. (2005). Role of NGOs in empowering the vulnerable women: A study on ACD. Asian Affairs, 27(4), 24-40.

Kabeer, N., Mahmud, S., \& Isaza Castro, J. G. (2012). NGOs and the political empowerment of poor people in rural Bangladesh: Cultivating the habits of democracy. World Development, 40(10), 2044-62. doi: 10.1016/j.worlddev.2012.05.011

Korten, D. C. (1990). Getting to the 21 Century: Voluntary action and the global agenda. Boulder: Lynne Rienner Publishers.

Ministry of Agriculture. (2006). [Bashgah-e keshavarzan-e javan project (Persian)]. Mashhad: Ministry of Agriculture.
Moghimi, M. (2004). [Entrepreneurship in civil society organizations (Research on non-governmental organizations NGOs in Iran) (Persian)] Tehran: Tehran University Press.

Najafi Abrandabadi, A. H. (15 April 2017). [Delinquency prevention and the department of neighbourhood police (Persian)] Donyay-e Hoghough. Retrieved from http://www.donyae-hoghough.com/\% D9\% BE\% DB\% 8C \% D8\% B4\% DA\%AF \%DB \% 8C \% D8 \% B1\%DB \% 8C- \% D8 \% A7\% D8\%B2-\%D8\%A $8 \% \mathrm{D} 8 \% \mathrm{~B} 2 \% \mathrm{D} 9 \% 87 \% \mathrm{D} 9 \% 83 \% \mathrm{D} 8 \% \mathrm{~A} 7 \% \mathrm{D} 8 \% \mathrm{~B} 1 \% \mathrm{DB} \% 8 \mathrm{C}-$ \%D9\%88-\%D9\%BE\%D9\%84\%DB\%8C\%D8\%B3-\%D9\%85\%D8\%$\mathrm{AD} \% \mathrm{D} 9 \% 84 \% \mathrm{DB} \% 8 \mathrm{C} /$

Namazi, B. (2001). [Check existing Iranian NGOs, Proceedings of the role of NGOs in the field of national and international activities (Persian)] Tehran: Office of Political Studies and the Ministry of Interior.

Newaz, W. (2000). Impact of NGO credit programs on the empowerment of rural women in Bangladesh: A case of UTTARAN. Paper presented at The Conference of the Third Sector: For What and For Whom Dublin, Ireland, 5-8 July 2000.

Ormozdi, M. (2011). [Requirements development policy review non-governmental organizations (NGOs), planning and management of rural tourism (Persian)]. Paper presented at The Conference of Tourism and Sustainable Development, Hamedan, Iran, 13-14 July 2011.

Osterwalder, A. (2003). Sustainable rural development in developing countries. Lausanne: University of Lausanne Pub.

Roknodin Eftekhari, A., \& Badri, A. (2012). [The foundations of the theory of development pattern typical village (Persian)]. Guilan: Governor of Guilan.

Saeedi, M. R. (2014). [Introduction to public participation and non-governmental organizations (Persian)]. Tehran: SAMT Publications.

Shahbahrami, F., Pishgahifar, Z., Zalpoor, K., \& Bakhtiyari, T. (2010). [The effect of non-governmental organizations on the prevention of the crime of female-headed households (Persian)]. Journal of Security Management, 5(3), 504-18.

Shakori, A. (2011). [Social contributions and support organizations (with Iran) (Persian)]. Tehran: SAMT Publications.

Sobhi Moghadam, M. (2014). [Local NGOs conditions, interactions and outcomes (Case study: Keykha Village, Zabol) (Persian)] (MSc. thesis). Tehran: Tarbiat Modarres University.

Srivastava, L., \& Austin, M. J. 2012. Women and non-governmental organizations in developing countries. Retrieved from http:/ / mackcenter.berkeley.edu/sites/default/files/publications/women and_non-governmental_organizations_in_developing_countries. pdf 